\title{
Is there a role for celiac plexus block for chronic pancreatitis?
}

Authors

Institution
Pietro Fusaroli, Giancarlo Caletti

Department of Gastroenterology, University of Bologna, Imola, Italy submitted

26. November 2014

accepted after revision

11. December 2014

\section{Bibliography}

DOI http://dx.doi.org/

10.1055/s-0034-1391392

Published online: 11.2.2015

Endoscopy International Open

2015; 03: E60-E62

(C) Georg Thieme Verlag KG

Stuttgart · New York

E-ISSN 2196-9736

\section{Corresponding author}

Pietro Fusaroli, MD

Department of

Gastroenterology

University of Bologna

Via Montericco 4

Imola

Italy

Fax: +39-05-426-62409

pietro.fusaroli@unibo.it
License terms

() (1) $\ominus \circledast$
Endoscopic ultrasound-celiac plexus block (EUSCPB) and endoscopic ultrasound-celiac plexus neurolysis (EUS-CPN) have been reported to provide pain relief and reduce narcotics use in patients with chronic pancreatitis [1]. The techniques of EUS-CPB and EUS-CPN are identical; the differences are in the substances injected and in the indications. Neurolysis, in which bupivacaine and ethanol are injected, has been used in patients who have pancreatic cancer or chronic pancreatitis. On the other hand, block, in which bupivacaine with or without triamcinolone is injected, has been used mainly in patients who have chronic pancreatitis [2].

The injection of ethanol, bupivacaine, and triamcinolone into the celiac plexus disrupts signal transmission to the spinal cord and central nervous system, theoretically interfering with the perception of pain. The effects of ethanol are much less reversible than the effects of bupivacaine and triamcinolone, and albeit rare, more severe adverse effects have been reported with EUS-CPN than with EUS-CPB [3-5]. Moreover, meta-analysis of EUS-CPN showed results in patients with pain due to chronic pancreatitis (pain relief in $59 \%$ of 376 patients in 9 studies) that were inferior to results in patients with pancreatic cancer (pain relief in $80 \%$ of 283 patients in 8 studies) [6]. For these reasons, EUS-CPN is the technique of choice for patients with pancreatic cancer, whereas EUS-CPB is preferred for patients affected with a benign condition, such as chronic pancreatitis.

Because of the anatomical location of the celiac plexus around the origin of the celiac trunk and superior mesenteric artery, the EUS-guided technique provides near-field and real-time visualization, resulting in a safer approach than is possible with percutaneous techniques [7]. A randomized, controlled trial, in which EUS-guided and fluoroscopy-guided percutaneous $\mathrm{CPB}$ with bupivacaine and triamcinolone were compared in patients who had chronic pancreatitis, demonstrated improvement in pain scores (visual analogue scale) in $70 \%$ of patients in the EUS group versus $30 \%$ of those in the percutaneous group $(P=0.044)$ [8]. However, the efficacy of EUS-CPB has been questioned because of inconsistent results in terms of the degree and duration of pain reduction in published studies [8-14] ( $\odot$ Table 1 ). A systematic review of the efficacy of steroid-based EUS-CPB in patients with refractory pain due to chronic pancreatitis (6 studies including 221 patients) showed satisfactory reduction of abdominal pain in only $51 \%$ of patients [15]. Moreover, in a study in which 40 patients were randomized to receive either bupivacaine alone or bupivacaine and triamcinolone, no significant difference in pain control was found between the two groups (14\% vs. $16 \%$ for controls) [14].

Sey et al. have offered an original perspective on the topic of EUS-CPB, addressing the problem of the short duration of its effects [16]. From a huge EUS-CPB database of 1108 patients treated at the Indiana University Medical Center, Indianapolis, Indiana, USA, they extrapolated data for $248 \mathrm{pa}-$ tients with chronic pancreatitis who underwent two or more procedures and investigated the incremental effects of repeated EUS-CPB procedures.

Either a standard 22-gauge needle or a dedicated 20 -gauge needle with sideholes at the end was used for EUS-CPB. When visible, the celiac ganglia were targeted; otherwise, $20 \mathrm{~mL}$ of $0.75 \%$ bupivacaine followed by 40 to $80 \mathrm{mg}$ of triamcinolone, according to the endosonographer's preference, was injected at the level of the celiac trunk.

The majority of the patients underwent 2 to 4 procedures, but some had 5 to 6 and a few of them even had up to 10 EUS-CPB procedures. After the first session, $76 \%$ of the patients reported pain relief, a value in line with the upper limit of the range of effectiveness reported in the literature. The median duration of pain relief was 10 
Table 1 Endoscopic ultrasound and celiac plexus block in chronic pancreatitis.

\begin{tabular}{|c|c|c|c|c|c|c|}
\hline Article & Study & Patients & Techniques & $\begin{array}{l}\text { Technical } \\
\text { success }\end{array}$ & $\begin{array}{l}\text { Clinical success } \\
\text { (pain relief) }\end{array}$ & Complications \\
\hline Gress et al., 1999 & RCT & $\begin{array}{l}\mathrm{n}=10 \\
\mathrm{n}=8\end{array}$ & $\begin{array}{l}\text { EUS-CPB } \\
\text { CT-CPB }\end{array}$ & $100 \%$ & $\begin{array}{l}50 \% \\
25 \%\end{array}$ & None \\
\hline Gress et al., 2001 & PS & $\mathrm{n}=90$ & EUS-CPB & $100 \%$ & $55 \%$ & 3 diarrhea \\
\hline Levy et al., 2008 & RS & $n=18$ & $\begin{array}{l}\text { EUS-CGN }(n=5) \\
\text { EUS-CGB }(n=13)\end{array}$ & - & $\begin{array}{l}80 \% \\
38 \%\end{array}$ & $\begin{array}{l}12 \text { hypotension } \\
6 \text { diarrhea }\end{array}$ \\
\hline O'Toole et al., 2009 & RS & $n=128$ & EUS-CPB & - & - & $\begin{array}{l}2 \text { post-procedural pain } \\
1 \text { retroperitoneal abscess } \\
1 \text { hypotension }\end{array}$ \\
\hline Santosh et al., 2009 & RCT & $\begin{array}{l}n=27 \\
n=29\end{array}$ & $\begin{array}{l}\text { EUS-CPB } \\
\text { Percutaneous CPB }\end{array}$ & $\begin{array}{l}100 \% \\
-\end{array}$ & $\begin{array}{l}70 \% \\
30 \%\end{array}$ & 2 diarrhea \\
\hline Leblanc et al., 2009 & RCT & $\begin{array}{l}n=23 \\
n=27\end{array}$ & $\begin{array}{l}\text { EUS-CPB (central) } \\
\text { EUS-CPB (bilateral) }\end{array}$ & $100 \%$ & $\begin{array}{l}65 \% \\
59 \%\end{array}$ & None \\
\hline Stevens et al., 2012 & RCT & $n=40$ & $\begin{array}{l}\text { Triamcinolone + bupivacaine }(n=21) \\
\text { Bupivacaine alone }(n=9)\end{array}$ & $100 \%$ & $68 \%-86 \%$ & $\begin{array}{l}1 \text { severe hypertension } \\
4 \text { pain exacerbation } \\
1 \text { gastric hematoma }\end{array}$ \\
\hline
\end{tabular}

RCT, randomized controlled trial; EUS, endoscopic ultrasound; CPB, celiac plexus block; CT, computed tomography; PS, prospective study; RS, retrospective study; CGN, celiac ganglia neurolysis; CGB, celiac ganglia block.

weeks. Subsequent EUS-CPB procedures produced fairly longer intervals of pain relief (12-20 weeks). Failure to obtain pain relief after the first EUS-CPB was associated with failure after subsequent EUS-CPB procedures. On the other hand, older age ( $P=$ $0.026)$ and pain relief after the first block $(P=0.0024)$ were associated with pain relief after subsequent EUS-CPB procedures. Finally, the number of EUS criteria for chronic pancreatitis was not associated with pain relief.

Given the nearly complete absence of complications (only $3 \mathrm{mi}-$ nor transient events occurred), the study of Sey et al. is a unique and interesting demonstration of the feasibility and efficacy of repeated EUS-CPB procedures to control pain in patients with chronic pancreatitis. Given the benign but chronic nature of chronic pancreatitis, these patients are natural candidates to undergo a treatment that is reasonably effective, safe, and repeatable.

The good results of the study from the Indiana University Medical Center agree with those of an ongoing randomized, multicenter trial comparing EUS-CPB (bupivacaine + triamcinolone) with a sham procedure, in which patients are blinded to the procedure, and should revive interest in EUS-CPB. In preliminary results, the rate of pain reduction was significantly higher in the treated arm than in the sham arm; morphine use was also reduced in the treatment group, although the difference between the treatment group and the sham group was not significant. Crossover to the active treatment was requested by $100 \%$ of the patients in the sham group after a median of 46 days [17].

In summary, according to this new evidence, EUS-CPB appears to be a safe, moderately effective, and repeatable treatment for patients with pain caused by chronic pancreatitis. Of course, recourse to EUS-CPB should be weighed against the alternative options that are available. These include lifestyle changes (e.g., cessation of alcohol and tobacco use), supplementation of pancreatic enzymes, and psychosocial support to reduce opiate dependence. For patients who have severe disease with main pancreatic duct dilatation, endoscopic or surgical duct decompression and total pancreatectomy with islet auto-transplantation are also options. Gastroenterologists must use their clinical judgment in order to select the patients who may benefit from EUSCPB (e.g., those who experienced relief after a previous EUS-CPB procedure and those who are elderly). On the other hand, pre- cious time should not be wasted on EUS-CPB when it is ineffective; in these cases, other treatments should be readily adopted before the disease becomes too advanced (with the development of excessive organ fibrosis and nociceptive pathway remodeling) to respond even to surgical treatment [18].

\section{Competing interests: None}

\section{References}

1 Penman ID, Rösch T. EUS 2008 Working Group. EUS 2008 Working Group document: evaluation of EUS-guided celiac plexus neurolysis/ block (with video). Gastrointest Endosc 2009; 69: 28-S31

2 Singla V, Garg PK. Role of diagnostic and therapeutic endoscopic ultrasonography in benign pancreatic diseases. Endosc Ultrasound 2013; 2: $134-141$

3 Gimeno-García AZ, Elwassief A, Paquin SC et al. Fatal complication after endoscopic ultrasound-guided celiac plexus neurolysis. Endoscopy 2012; 44: E267

4 Loeve US, Mortensen MB. Lethal necrosis and perforation of the stomach and the aorta after multiple EUS-guided celiac plexus neurolysis procedures in a patient with chronic pancreatitis. Gastrointest Endosc 2013; 77: $151-152$

5 Jang HY, Cha SW, Lee BH et al. Hepatic and splenic infarction and bowel ischemia following endoscopic ultrasound-guided celiac plexus neurolysis. Clin Endosc 2013; 46: 306-309

6 Puli SR, Reddy JB, Bechtold ML et al. EUS-guided celiac plexus neurolysis for pain due to chronic pancreatitis or pancreatic cancer pain: a metaanalysis and systematic review. Dig Dis Sci 2009; 54: 2330-2337

7 Wiersema MJ, Wiersema LM. Endosonography-guided celiac plexus neurolysis. Gastrointest Endosc 1996; 44: 656-662

8 Santosh D, Lakhtakia S, Gupta R et al. Clinical trial: a randomized trial comparing fluoroscopy guided percutaneous technique vs. endoscopic ultrasound guided technique of coeliac plexus block for treatment of pain in chronic pancreatitis. Aliment Pharmacol Ther 2009; 29: 979984

9 Gress F, Schmitt C, Sherman $S$ et al. A prospective randomized comparison of endoscopic ultrasound- and computed tomography-guided celiac plexus block for managing chronic pancreatitis pain. Am J Gastroenterol 1999; 94: 900-905

10 Gress F, Schmitt C, Sherman S et al. Endoscopic ultrasound-guided celiac plexus block for managing abdominal pain associated with chronic pancreatitis: a prospective single center experience. Am J Gastroenterol 2001; 96: 409-416

11 Levy MJ, Topazian MD, Wiersema MJ et al. Initial evaluation of the efficacy and safety of endoscopic ultrasound-guided direct ganglia neurolysis and block. Am J Gastroenterol 2008; 103: 98-103 
12 O'Toole TM, Schmulewitz N. Complication rates of EUS-guided celiac plexus blockade and neurolysis: results of a large case series. Endoscopy 2009; 41: $593-597$

13 LeBlanc JK, DeWitt J, Johnson C et al. A prospective randomized trial of 1 versus 2 injections during EUS-guided celiac plexus block for chronic pancreatitis pain. Gastrointest Endosc 2009; 69: 835-842

14 Stevens $T$, Costanzo A, Lopez $R$ et al. Adding triamcinolone to endoscopic ultrasound-guided celiac plexus blockade does not reduce pain in patients with chronic pancreatitis. Clin Gastroenterol Hepatol 2012; 10: $186-191$

15 Kaufman M, Singh G, Das $S$ et al. Efficacy of endoscopic ultrasoundguided celiac plexus block and celiac plexus neurolysis for managing abdominal pain associated with chronic pancreatitis and pancreatic cancer. J Clin Gastroenterol 2010; 44: 127-134

16 Sey MSL, Schmaltz L, Al-Haddad MA et al. Effectiveness and safety of serial endoscopic ultrasound-guided celiac plexus block for chronic pancreatitis. Endoscopy International Open 2015; 03: 24 Oct 2014 (eFirst). DOI 10.1055/s-0034-1377919

17 Eisendrath $P$, Paquin SC, Delhaye $M$ et al. A randomized, double-blinded, multi-center, sham-controlled trial of EUS-guided celiac plexus block for pain due to chronic pancreatitis. Gastrointest Endosc 2014; 79: AB168

18 Bellin MD, Freeman ML, Gelrud A et al. Total pancreatectomy and islet autotransplantation in chronic pancreatitis: recommendations from PancreasFest. Pancreatology 2014; 14: 27-35 